\title{
Clubfoot Associated with Nail-patella Syndrome. Evolution and Treatment with Ponseti Method
}

\section{Ey Batlle Ana Maria*, Vinyals Rodriguez Marta and Míguez Gonzalez Paula}

Equipo Ponseti Dra. Anna Ey, Clinica Diagonal (Barcelona), Spain

*Corresponding Author: Ey Batlle Ana Maria, Equipo Ponseti Dra. Anna

Ey, Clinica Diagonal (Barcelona), Spain.

DOI: 10.31080/ASOR.2022.05.0426
Received: December 03, 2021

Published: February 18, 2022

(C) All rights are reserved by Ey Batlle Ana

Maria., et al.

\begin{abstract}
Introduction: The incidence with clubfoot, is about 1 to 7/1000 newborns bat its association with Nail Patella Syndrome has never been reported and there are no series of homogeneous treatment of clubfoot associated with this syndrome. Nail-Patella Syndrome is an hereditary onycho-osteodysplasia which has an incidence rate estimated at 1/45.000 newborns. Patients may have hypoplastic or absent patella, dysplastic elbows and iliac exostoses. There may also be renal and ophthalmic alterations.

Objective: To evaluate function and quality of life in patient with clubfoot associated with Nail-Patella Syndrome treated by Ponseti Technique, and to describe its results.

Materials and Methods: Retrospective study of 4 patients ( $\mathrm{n}=8$ feet) treated by Ponseti Technique. The cases were evaluated with detailed medical history, physical examination, total number of casts made for the foot correction, associated complications, description of associated onychopathies, initial correction obtained (Pirani Score), percentage of percutaneous Achilles tenotomy performed, recurrence rate of relapses, tolerance of abduction braces and morphology and foot function. For statistical analysis Chi-square test have been used. Chi-square tests were used in comparison with categorical variables, and expressed as numbers and percentages.

Results: Follow up 4-14y. All cases required between 3-4 casts. All cases required percutaneous Achilles tenotomy. No patient has suffered signs of deformity relapse. According to Laaveg-Ponseti scale, the functional results obtained are 98.6/100. No patient presents residual deformity or complication of any note. Functionally, all 8 feet are painless.

Conclusions: Ponseti Technique is a good method for treatment of clubfoot associated with Nail-Patella Syndrome. It obtains excellent results without any need for additional aggressive surgical treatment.
\end{abstract}

Keywords: Nail Patella Syndrome; Clubfoot; Ponseti Method; Syndromic Clubfoot

\section{Introduction}

Congenital clubfoot is one of the most common birth defects, its prevalence is about 1 to 7:1000 live births, it consist of a malalignment of joints and bones in the foot that appears at 12-16 weeks of pregnancy. Twenty percent of cases are associated with other problems such as arthrogryposis, myelomeningocele, neurological disease or genetic syndromes [1-3].
Clubfoot treatment has changed from the aggressive surgical techniques of the 80's to the "gold standard" Ponseti Method. The Ponseti Method is based on the knowledge of anatomy and physiopathology of clubfoot. The baby is treated with serial casting, Achilles tenotomy if needed and braces up to 4 or 5 years of age. The risk of relapse in clubfoot is between $15 \%$ to $40 \%$ based on the differing opinion of the authors in various medical papers. With the Ponseti Method when a clubfoot suffers a relapse the Anterior Tibial Ten- 
don Transfer could be required and in cases that are absolutely resistant to the different periods of treatment there may be need of osseous surgery $[4,5]$.

The Nail-Patella Syndrome is an hereditary onycho-osteodysplasia, with an incidence estimated to be about $1 / 45.000$ newborns. Patients with Nail-Patella Syndrome may have hypoplastic or absent patella "Figure 1", dysplastic elbows and iliac exostoses. There may also be renal and ophthalmic alterations.

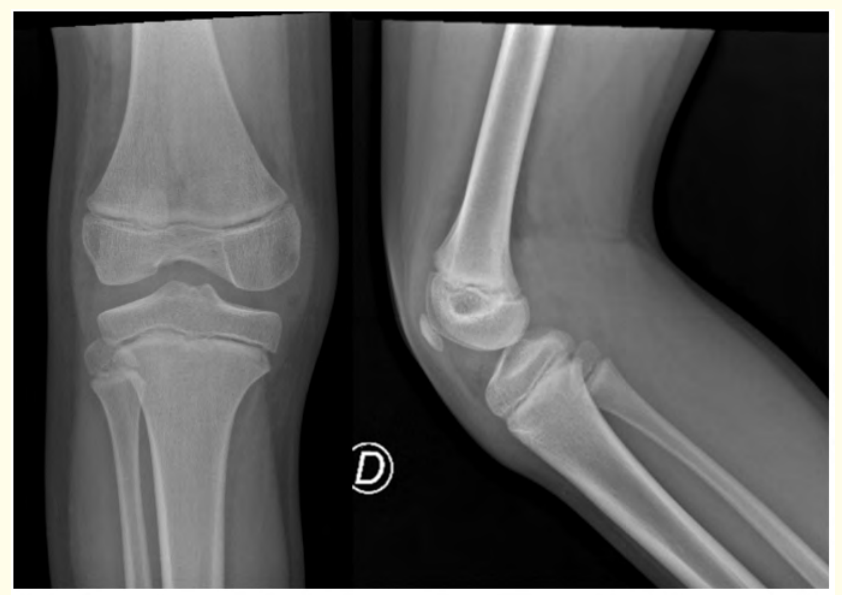

Figure 1: Knee X-Ray of a patient with the dysplastic patella.

The incidence of clubfoot in patients with Nail Patella Syndrome has never been reported, furthermore there are no homogeneous treatment study groups of clubfoot patients associated with this syndrome [10-14].

When Clubfoot deformity is associated with a Syndrome it could result in the correction of the deformity being more resistant to treatments and the response to the therapy is conditioned by the Syndrome characteristics [7-10].

\section{Material and Methods}

We perform a retrospective study of patients with Nail-Patella Syndrome associated with Clubfoot. A total of 4 patients (8 feet) were included in this case study.

All patients were treated at the same institution from 2005, and the last follow-up was done in 2020.

The patients were enrolled in Ponseti Protocol as it was described: Serial casting, Achilles percutaneous tenotomy and Braces up to 4 years of age.
The cases were evaluated with detailed medical history and physical examination at last follow-up.

The following parameters are registered:

- Age at beginning of Ponseti protocol

- Total number of casts made for the foot correction

- Tenotomy

- Complications

- Follow up

- $\quad$ Previous treatment

- Associated onychopathies

- Initial correction obtained

- Relapses

- Abduction braces tolerance

- Foot function.

- Foot morphology and dorsiflexion

- Pain

The four cases are recorded in a "Figure a" of results.

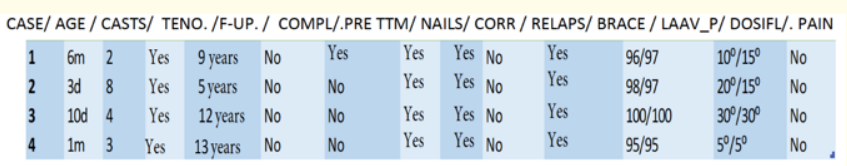

Figure a: Results obtained in the 4 patients.

All patients agree to sign a consent to participate in this study and we obtained permission from the Ethics Committee of Clínica Diagonal (Barcelona).

\section{Results}

The results of the four patients and their eight feet are described in "Figure a".

The patients had a follow up from 5 years to 13 years, one case had been treated previously with a conservative treatment and tenotomy in another institution and was considered as an atypical clubfoot.

The age at beginning of treatment was in first month of life with the exception of the atypical case, the one which was previously treated, this case began the treatment at 6 months of age. 
The number of casts required to correct the initial deformity were 3 to 8 .

The Achilles tenotomy was done in all cases and in one patient a second tenotomy was performed. These results differ from the analysis described by other authors whose case studies include Sydromic clubfoot treatment and hence whose analysis does not concentrate specifically and uniquely on patients sufferinfg NailPatella Syndrome [7-9].

All the patients studied had nail dystrophy, affecting the thumb and first toe "Figure 2".

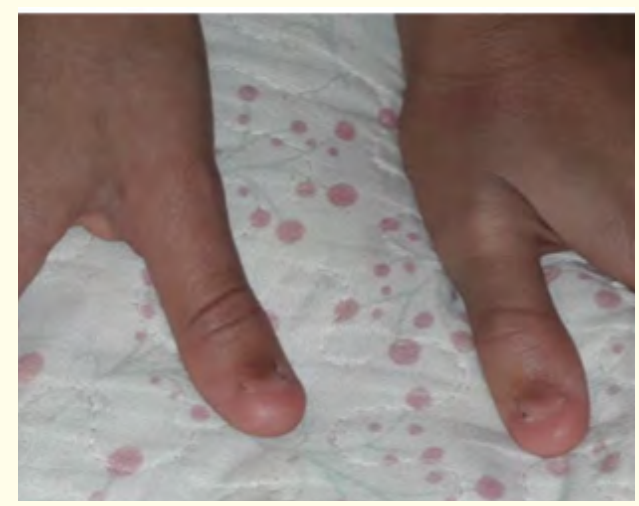

Figure 2: Both hands in an affected patient that shows the Nail changes in both thumbs.

In the final follow up no patient developed any sign of relapse, so no one needed an anterior tibial tendon transfer. There were no complications related to the Ponseti Method in this group.

No patient presented a residual deformity or pain "Figure 3".

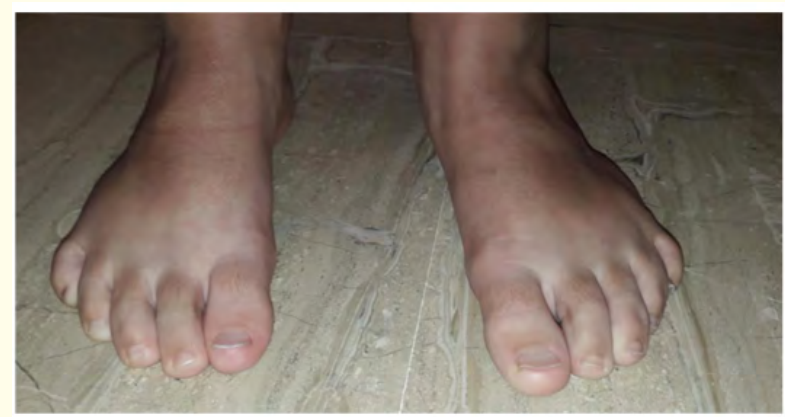

Figure 3: Bilateral Clubfeet associated to Nail-Patella Syndrom, 12 year follow -up after Ponseti treatment.
And no aggressive surgeries are planned in future as a consequence of the last follow up.

The range of motion was good in all cases, the dorsiflexion ranged from 5 degrees to 20 degrees with an average of 13 degrees.

Functional evaluation was done according to the Laaveg- Ponseti scale and the results obtained were 98.6/100 points. Excellent results in all cases.

\section{Discussion}

Syndromic clubfeet are an heterogenic group of patients and need to be differentiated according with the special characteristics of the Syndrome.

Most papers have described a bad response to conservative treatment in cases of non-idiopathic clubfeet [6-9] but it is important to note that to date the authors have combined different syndromes with their variable prognosis in their studies wich results in a lack of precision. In the group of Nail Patella Syndrome that we have treated we did not find any signs of insufficient response to conservative treatment.

We achieved a $100 \%$ of initial correction with Ponseti method in this group of patients, no relapses were observed, and the functional Score of Lavegg-Ponseti shows excellent results in all patients.

It's important to include the observation of the nail of both hands and feet in babies with clubfoot and to perform a total clinical examination, especially with knees to detect the hypoplastic or absent patella [14].

To our knowledge there are no homogenic groups of patients described with both Nail-Patella Syndrome and clubfeet treated with the Ponseti method. Currently the Ponseti method is the "gold standard". The protocol has to be followed strictly in order to obtain the good results described by Ponseti. The clubfoot associated Nail-Patella Syndrome has demonstrated the same good results as other series of idiopathic clubfoot. We firmly believe that this combination Nail Patella and clubfoot will be healed with the application of the Ponseti technique.

It is possible that with a longer follow-up or wider case study the index of relapse may increase from zero to the normal rate when a brace is used properly (about 15\%), because one of the 
limitations of our study is the limited number of patients. It has been described that patients with hyperlaxity have protection to relapse, this could be considered one of the factors to obtain good results in this selected group.

Nail Patella Syndrome is a rare entity and its association to clubfeet has been described in some papers, the significance of this study is that it is the first case study that describes the results using the same Ponseti protocol.

\section{Conclusions}

- The Nail-Patella Syndrome does not affect negatively the clubfoot treatment response

- $\quad$ Patients with Nail Patella Syndrome have shown a low rate of relapse.

- $\quad$ Ponseti Method obtains excellent results without any need for aggressive surgical treatment.

\section{Bibliography}

1. Ponseti IV. "Congenital clubfoot: Fundamentals of Treatment". Oxford University Press $2^{\text {nd }}$ edition. January (1996).

2. Staheli L., et al. "Clubfoot: Ponseti management". Third edition. www.global-help.org (Date last accessed 1 November) (2010).

3. Laaveg SJ and Ponseti IV. "Long term results of treatment of congenital clubfoot". Journal of Bone and Joint Surgery 62-A (1980): 23-31.

4. R Viladot. Anna Ey, 25 Lecciones de patología del pie R. Viladot Voegeli y R Viladot Pericé. III Capitulo de tratamiento de pie equinovaro PUNTO ROJO LIBROS S.L (2020).

5. Ey Batlle Anna. "Tratamiento del pie equinovaro Revista Española de pie y tobillo". 31.1 (2017).

6. Van Bosse HJP. "Challenging clubfeet: the arthrogrypotic clubfoot and the complex clubfoot". Journal of Children's Orthopaedics 13 (2019): 271-281.

7. Janicki JA., et al. "Treatment of neuromuscular and syndromeassociated (non-idiopathic)clubfeet using the Ponseti method". Journal of Pediatric Orthopaedics (2009) 29:393-7.

8. Moroney PJ., et al. "A single-center prospective evaluation of the Ponseti method in nonidiopathic congenital talipes equinovarus". Journal of Pediatric Orthopaedics 32 (2012): 636-640.
9. Abraham J., et al. "Ponseti Casting vs.Soft Tissue Release for the Initial Treatment of Non-idiopathic Clubfoot". Fronters in Surgery 8 (2021): 668334.

10. Konrads C., et al. "Nail-patella-syndrome in a young patient followed up over 10 years: relevance of the sagittal trochlear septum for patellofemoral pathology". SICOT Journal 2 (2016): 26.

11. Ghoumid J., et al. "Nail-Patella Syndrome: clinical and molecular data in 55 families raising the hypothesis of a genetic Heterogeneity". European Journal of Human Genetics 24 (2016): 44-50.

12. Rushabh M Vakharia., et al. "Robotic-Assisted Lateral Unicompartmental Knee Arthroplasty in a Patient With Nail-Patella Syndrome". Arthroplasty Today 8 (2021): 171e175.

13. Alvarado D M., et al. "Familial Isolated Clubfoot Is Associated with Recurrent Chromosome 17q23.1q23.2 Microduplications Containing TBX4". American Journal of Human Genetics 87 (2010): 154-160.

14. Sanke S., et al. "Nail Patella Syndrome a classic case". Dermatology Practical and Conceptual 9.4 (2019): 271.

\section{Assets from publication with us}

- Prompt Acknowledgement after receiving the article

- Thorough Double blinded peer review

- Rapid Publication

- Issue of Publication Certificate

- High visibility of your Published work

Website: www.actascientific.com/

Submit Article: www.actascientific.com/submission.php

Email us: editor@actascientific.com

Contact us: +919182824667 